\section{La pobreza en Chile y su superación como problema de estado: Un análisis de los discursos presidenciales de la concertación}

Poverty in Chile and its success as a problem of state: an analysis of presidential speeches of conciliation

\section{RAYÉn RoviRA-RuBio*}

\section{Resumen}

El artículo recoge los principales resultados de la tesis doctoral que tiene por título el mismo nombre, en la que indago en cómo el Estado chileno definió la pobreza como problema social y al pobre como sujeto de gobierno, especialmente entre los años 1990 y 2010. Para

Doctora en Psicología Social Universidad Autónoma de Barcelona, España. Tesis doctoral disponible en http://www.tdx. cat/handle/10803/285126. Programa de Psicología, Facultad de Ciencias Sociales y Humanas, Universidad de Manizales, Colombia. Correo electrónico: rrovira@umanizales.edu.co. la investigación, se utilizó como estrategia el Análisis Crítico del Discurso (Fairclough 1989; van Dijk y Mendizábal 1999) para analizar un corpus constituido por mensajes del 21 de mayo emitidos por los gobiernos liderados desde el conglomerado político conocido como Concertación de Partidos por la Democracia. Se concluye que el discurso acerca de la superación de la pobreza posiciona una identidad social del pobre como factor de inclusión social, siendo criterio base para ser beneficiario de las políticas sociales, en la que se plantea la pobreza como un problema principalmente del pobre y la intervención social del Estado como necesaria ante la incapacidad de estos de poder superarla por sí mismos.

Palabras clave: Pobres, pobreza, Análisis Crítico del Discurso, política social, Chile.

\begin{abstract}
This article summarizes the main results of the thesis of the same name, in which we studied how the Chilean government defined poverty as a social problem and the poor as a subject of government between 1990 and 2010. The strategy used for the investigation was Critical Discourse Analysis (Fairclough 1989; van Dijk \& Mendizabal 1999), which was applied to analyse a corpus consisting of messages issued by governments from the Coalition of Parties for Democracy on May, $21^{\text {st. }}$ It is concluded that the discourse about the confrontation of poverty establishes a social identity of the poor as a principle of social inclusion, setting this as a basic criterion for the benefit of social policies, considering poverty as a problem that belongs mainly to the poor and the social intervention as
\end{abstract}


necessary due to the inability of poor people to overcome their condition by themselves.

Key words: Poor, poverty, Critical Discourse Analysis, social policy, Chile.

\section{Introducción}

Al inicio de los años 1990, con el término de la dictadura militar, la lucha contra la pobreza fue asumida por los gobiernos de la Concertación de Partidos por la Democracia (CPPD) como uno de los objetivos más importantes del Estado, en un Chile reconocido internacionalmente por sus condiciones de pobreza e injusticia social (Schkolnik y García 1995). Tras esta tarea, se planteó dar respuestas a las necesidades de la población y a las demandas sociales más urgentes de abordar al inicio de esa década, de cara a la estabilidad democrática del país (Moriconi 2009).

El objetivo recién mencionado se concretó por medio de dos líneas de acción. La primera de ellas fue la estimulación del desarrollo de la economía por la vía liberal, en consonancia con los lineamientos emergentes en dictadura, lo que trajo consigo un incremento de recursos económicos y un desarrollo de la industria y, en consecuencia, una reducción en los niveles de cesantía en la población (Garretón 2013). Esta estrategia se proyectó con gran relevancia en una sociedad donde la mayoría de los ingresos familiares han tenido como fuente principal los sueldos y/o salarios de los trabajadores (Solimano y Pollack 2006). Por otra parte, la segunda línea se implementó a través de la creación de nuevas entidades gubernamentales, con el apoyo de la fuerza política y social de los organismos no gubernamentales generados en los años 1980, contestatarios al régimen militar, quienes se sumaron al quehacer político en áreas clave de las políticas sociales orientadas, principalmente, a la mejora de las condiciones de vida de la población más carente de recursos, impulsadas desde los nuevos ministerios, las secretarias de gobierno, departamentos, etc. (DelaMaza 2005).

Las prácticas de la naciente política social post dictadura se centraron en la implementación de múltiples programas sociales, que en un primer momento se enfocaron en dar respuestas a necesidades del ámbito tradicional de la política social (vivienda, educación y salud), para posteriormente sumarse a prácticas destinadas a grupos identificados como de extrema pobreza y/o vulnerable con el objetivo de mejorar las condiciones de vida de la población más pobre (Raczynski 1995).

Sin embargo, el proceso de focalización de las políticas orientadas a la superación de la pobreza se realizó conservando tecnologías para medir la pobreza en el país elaboradas durante la dictadura militar ${ }^{1}$, las cuales utilizaban sistemas de medida absolutos, y desde los que se considera pobre a quienes tienen ingresos o gastos agregados inferiores a un valor equivalente al definido como necesario para la subsistencia (Ministerio de Planificación y Cooperación MIDEPLAN 2002)2. De este

A nivel ministerial se utilizó, desde el año 1980, el cálculo de la línea de la pobreza (LP), con el objetivo de hacer un mapa de la pobreza en Chile y priorizar la destinación de recursos. Luego, desde 1985, se utilizó la Encuesta de Caracterización Socioeconómica (CASEN) para medir el impacto de las políticas implementadas (Fundación para la superación de la Pobreza y Universidad Diego Portales 2011). Mientras tanto, a nivel municipal se recurrió a la ficha CAS-2 desde 1980, para la focalización de programas sociales desarrollados en ese nivel (Herrera, Larrañaga y Telias 2010).

2 Este ministerio actualmente se Ilama Ministerio de Desarrollo Social (desde 2011). 
modo, la pobreza se ha acotado a la carencia de recursos materiales y su superación se ha ligado a la mayor adquisición de los mismos por la vía económica, o bien por medio de la acción desde políticas sociales. Es tras estas lógicas de accionar en la materia que Chile se definió como carente en el año 1990, con un indicador de pobreza de un $38,6 \%$ de acuerdo a los sistemas de medida de la época y más tarde, en 2009 , fue descrito como un país que logra superar la pobreza, reduciéndola a un 15,1\% (Fundación para la Superación de la Pobreza FOSUPO y Universidad Diego Portales 2011).

A lo anterior se agregaron nuevos diagnósticos internacionales, donde se reconoce a Chile como el país que posee el mayor índice de desarrollo humano del continente ${ }^{3}$ (Programa de Naciones Unidas para el Desarrollo o PNUD 2013) y que se encuentra ad portas de ser el único "país desarrollado" del cono sur, incorporado en 2010 a la Organización para la Cooperación y el Desarrollo Económico u OCDE (2010).

Es en este escenario que la presidenta Michelle Bachelet -en su primera administración- dio por cumplida en gran medida la labor de las políticas sociales relativas a la superación de la pobreza y propuso su reorientación hacia un nuevo objetivo: generar un sistema de protección social (Bachelet 2005). Sin embargo, este éxito contrastó con el nivel de inequidad prevaleciente hasta 2010, cuando, de acuerdo al índice $\mathrm{Gini}^{4}$, Chile tenía una diferencia de 50,8

"El Índice de Desarrollo Humano (IDH): mide el progreso general de un país en tres dimensiones básicas: la longevidad, los conocimientos y un nivel de vida adecuado, a partir de la esperanza de vida, el nivel educacional y el ingreso per cápita ajustado por la paridad del poder adquisitivo" (MIDEPLAN 2002:6).

4 El coeficiente de Gini es un número entre 0 y 1 , en donde 0 se corresponde con la perfecta igualdad (todos tienen los mismos ingresos) y 1 se corresponde con la perfecta desigualdad (una entre el grupo social más rico y el más pobre (Banco Mundial 2014), con una concentración de la riqueza en la actualidad donde el $1 \%$ de los chilenos más ricos recibe lo mismo en ingresos que el $41 \%$ más pobre (Jackson 2013). Además, se ha conocido la necesidad de actualizar los sistemas de medida de la pobreza utilizados hasta la fecha por el gobierno, particularmente la Encuesta CASEN, que presentó inconsistencias en su aplicación del año 2002 debido a su desactualización (Fundación para la Superación de la Pobreza 2006) 5 .

Por otra parte, en cuanto a las condiciones de vida de aquellos identificados como pobres, desde inicios del 2000 se habían comenzado a ver influenciadas por las nuevas variables asociadas a la vía de crecimiento económico, las que implicaron, entre otras cosas, el acceso a recursos por medio del endeudamiento y sobreendeudamiento. Esta situación tuvo mayor incidencia en los hogares de menores recursos, donde se comienza a acceder a créditos de casas comerciales con intereses elevados, provocándose grandes acumulaciones de deuda (Chovar, Elgueta y Salgado 2009). Los créditos se configuraron como un elemento constitutivo del presupuesto familiar, que posibilitó el acceso a productos y servicios que no podrían ser obtenidos de otro modo, y siendo utilizados por las familias incluso para abastecerse de alimentos y artículos de uso

persona tiene todos los ingresos y los demás ninguno). Se calcula utilizando la Curva de Lorenz, a partir de la cual se determina un cociente entre la distribución real y una distribución perfectamente igualitarial (MIDEPLAN 2002).

5 En la primera administración de la presidenta Bachelet se creó el Consejo Asesor de Trabajo y Equidad, desde el cual se desarrollaron propuestas que, finalmente, no fueron incorporadas a la actualización del sistema recomendado por el Consejo. Al respecto, se llegó a plantear que la actualización implicaría un alza considerable del 15,1\% que registró la encuesta CASEN de 2009 (FOSUPO y Universidad Diego Portales 2011). 
diario. Esta dinámica incidió en la significación de la pobreza, en cuanto medida absoluta de la misma (Barros 2012).

Este escenario caló hondo en la población chilena, lo que fue confirmado por diversos estudios que, en 2011, desvelaron una abierta desconfianza por parte de la población hacia las instituciones y su capacidad de dar respuestas satisfactorias a los problemas sociales (Mayol 2012). De la misma forma, dichos estudios reflejaron la percepción ciudadana de que la pobreza seguía siendo uno de los grandes problemas del país (Centro de Estudios Públicos 2011), lo que quedó de manifiesto públicamente con las masivas movilizaciones por la educación, demostración del malestar social (Jackson 2013).

En este marco, resulta evidente que el éxito en la superación de la pobreza asumida desde la métrica gubernamental no ha considerado la medición de esa condición en función de la percepción de la sociedad en su conjunto, tal como resulta notoria una abierta desvinculación entre la superación de la pobreza y la reducción de inequidad de ingresos, que repercute en la prevalencia de marcadas divisiones sociales.

Ante este escenario, la presente investigación plantea una primera pregunta: ¿Cómo fue posible que la pobreza se planteara como un problema casi superado, mientras en la sociedad chilena todavía se percibía como uno especialmente importante en el año 2010? Posteriormente, esta interrogante se traduce en el siguiente objetivo de investigación: analizar el modo en que el Estado chileno definió la pobreza como problema social y al pobre como sujeto de gobierno entre 1990-2010 y determinar en qué medida esas definiciones contribuyeron a la prevalencia o modificación de las estructuras sociales en Chile. Los principales aspectos de la investigación, organizados en de acuerdo al objetivo mencionado, se describen a continuación.

\section{Corpus}

Los documentos que constituyeron el corpus de estudio fueron los mensajes presidenciales del 21 de mayo emitidos por los gobiernos de la CPPD entre los años 1990 y 2010.

Los mensajes del 21 de mayo son discursos políticos emitido por el Presidente (a) de la República, los que tradicionalmente han constituido la Cuenta Anual con la que se abre el período legislativo. Por ende, en ellos se exponen los temas prioritarios de la agenda de gobierno a legislar, junto con las principales acciones realizadas en el año anterior. Su primer interlocutor es el Parlamento, seguido por la población chilena en general, quien acciona como audiencia en tanto se trata de un discurso trasmitido para todo Chile por televisión abierta e Internet y que, además, se realiza en un día festivo en el calendario nacional.

El discurso del 21 de mayo es una tradición que data de inicios de la república, y fue obligatorio y no público hasta 1973. Más tarde su realización fue anulada, siendo retomada por los gobiernos de la CPPD, aunque sin obligatoriedad legislativa hasta el año 2005 (Riffo 2008). Dados estos antecedentes, su temprana apertura pública en los años 90s se puede interpretar como una estrategia política de la CPPD para dar cuenta al país de las prioridades del gobierno, así como también de las tensiones con el parlamento en algunos ámbitos relevantes de legislar. 
$\mathrm{Si}$ bien estos mensajes no se refieren exclusivamente a problemas de pobreza, fueron seleccionados como corpus por permitir comprender la pobreza como una cuestión de Estado, situándola en relación a los demás problemas a gobernar, con sus diferencias y solapamientos a lo largo del período estudiado. Esto permite visualizar con claridad tanto los cambios y continuidades en relación al discurso de gobierno acerca de la pobreza y los pobres, como también los actores y relaciones implicados en la definición del fenómeno.

Se analizaron, particularmente, sus transcripciones oficiales de carácter público ${ }^{6}$, constituyendo un corpus de 854 páginas. Luego, por medio de la recurrencia léxica de pobre y pobreza, se procedió a la identificación de los tópicos que referían específicamente a la temática, para cada mensaje presidencial.

Posteriormente, se identificaron cuatro fases en relación al discurso de la pobreza. Las fases fueron identificadas de acuerdo a los cambios en los tópicos vinculados al fenómeno y a los cuatro períodos presidenciales acontecidos entre los años 1990 y 2010. Estos fueron: I Período, presidido por Patricio Aylwin Azócar entre los años 1990-1994; II Período, presidido por Eduardo Frei Ruíz-Tagle entre 1994 y 2000; III Período, presidido por Ricardo Lagos Escobar entre los años 2000 y 2006; y IV Período, presidido por Michelle Bachelet Jeria entre 2006 y 2010.

Los discursos del 21 de mayo se obtuvieron de los archivos de la Cámara de Diputados de Chile, disponibles en línea en http:// www.camara.cl/camara/historia archivo.aspx

\section{Encuadres para el análisis crítico del discurso de la pobreza}

La estrategia de análisis utilizada en la presente investigación fue el Análisis Crítico del Discurso (ACD), que resulta ser una opción dentro de los estudios del discurso. Su elección se debió, principalmente, a su énfasis en hacer explícitas las relaciones de poder que con frecuencia se hallan ocultas, con un afán particular en obtener resultados que tengan relevancia práctica en sus ámbitos de producción (Meyer 2003). Además, una cualidad fundamental de la asunción de esta estrategia de análisis es que contempla el discurso como un producto histórico y que, por ende, su compresión y análisis solo resulta posible en tanto se tiene como referencia su contexto (Meyer 2003).

En el campo del ACD, existen distinciones acerca de la relación entre lenguaje y sociedad que articula el contexto. La presente investigación se basó, fundamentalmente, en el enfoque propuesto por el analista Norman Fairclough $(1989,2003)$, quien plantea que toda práctica social tiene componentes semióticos y que el análisis resulta ser, principalmente, de las relaciones dialécticas entre la semiosis y otros elementos de las prácticas sociales, siendo el aspecto semiótico del orden social lo que él denomina orden del discurso, siguiendo la propuesta dada por Michel Foucault acerca del discurso (Meyer 2003).

De la misma forma, para Fairclough (1989) el discurso es texto, interacción y contexto: texto, en tanto sistema de creencias y de conocimiento de la realidad; interacción, en tanto los sujetos interpretan los textos desde un conjunto de recursos discursivos socialmente disponibles; y contexto, porque se sitúa en un marco institucional del evento discursivo. 
En el caso de los textos analizados, el contexto de análisis está delimitado por el campo de los discursos políticos a los que corresponden los mensajes del 21 de mayo, siendo emitidos por políticos en contextos políticos (Van Dijk 1999). En esta línea, se siguió la sistematización del contexto del discurso político propuesto por el analista crítico Teun van Dijk (1999), lo que describiremos brevemente para este estudio.

Tras este modo de comprensión del discurso y su análisis, en la presente investigación se construyó una herramienta particular para indagar en la significación de la pobreza y de las acciones para su superación, a la que se denominó análisis de las racionalidades de gobierno. Para ello se comprendieron, primeramente, las racionalidades desde un enfoque foucaultiano del discurso; es decir, compuesto por la articulación de discursos de verdad, por medio de los cuales se constituyen modos de pensar y actuar sobre la población (Barry, Osborne y Rose 1996). En este caso, se analizaron racionalidades acerca del fenómeno de la pobreza.

Para la realización de este ejercicio metodológico, se procedió de un modo innovador, definiendo operativamente las racionalidades de gobierno acerca de la pobreza compuestas por: a) conocimientos o saberes, explícitos o presupuestos o implícitos, asumidos como tales por el gobierno; b) actitudes, comprendidas como acciones expresadas en el discurso por medio de actos de habla (declarativos de promesas, de denuncia, etc.) (Paz 2011); c) valoraciones de las acciones, pesquisadas desde la dimensión de la modalidad expresiva (Fairclough 1989); y d) ideologías u órdenes de discurso mediante los cuales se entrelazan los conocimientos y las acciones, expresadas en la presentación del problema central que constituye la pobreza en el discurso y los argumentos hegemónicos otorgados como parte del mismo.

Tabla 1. Componentes de las definiciones operativas de las racionalidades de gobierno acerca de la pobreza

\begin{tabular}{|l|l|}
\hline $\begin{array}{l}\text { Racionalidades } \\
\text { de gobierno }\end{array}$ & Categorías \\
\hline Conocimientos & $\begin{array}{l}\text {-Explícitos } \\
\text {-Implícitos }\end{array}$ \\
\hline Actitudes & $\begin{array}{l}\text {-Acciones } \\
\text {-Valoraciones }\end{array}$ \\
\hline Ideologías & $\begin{array}{l}\text {-Presentación del problema } \\
\text {-Argumentos persuasivos }\end{array}$ \\
\hline
\end{tabular}

Fuente: Elaboración propia.

A partir de estas herramientas, se analizó la significación de la pobreza en los distintos períodos de gobierno de la CPPD.

Además, en la investigación también se identificó el modo en que se comprendió al pobre como sujeto de gobierno. Para este ejercicio, se procedió mediante la aplicación herramientas del ACD planteado por Norman Fairclough como Análisis Tridimensional, particularmente a la utilización de herramientas cuya aplicación propone durante una fase identificada como fase del análisis descriptivo del texto (Fairclough 1989), para posteriormente llevar a cabo un análisis en relación al contexto.

Durante el análisis descriptivo, se indagó en los valores experienciales léxicos y sintácticos, 
poniendo especial atención en las diferencias ideológicas de los discursos que se representan en el texto, dónde el vocabulario puede estar ideológicamente marcado y en la colocación de las palabras. El análisis de estos valores permite revelar los conocimientos y/o creencias que llevan en su contenido (Fairclough 1989). Por esa razón, se indagó en los significados ideologizados de las palabras, la utilización de transferencias metafóricas y los tipos de agencia presentes (animada, inanimada) en relación a los modos de comprender a los sujetos en condición de pobreza.

También se analizó el uso de pronombres, como parte de los valores relacionales de la sintaxis, comprendiéndolo como un medio por el cual se revelan las relaciones de poder y de solidaridad, (por ejemplo, al utilizar un "nosotros" inclusivo o exclusivo al hacer referencia a la relación del emisor del discurso con un conjunto de otras personas).

A continuación pasaremos a exponer brevemente las condiciones contextuales, tal como también los principales resultados de la investigación obtenidos con las herramientas descritas.

\section{Contexto del discurso político de la pobreza de los mensajes del 21 de mayo}

Se definió el contexto del discurso político, siguiendo a van Dijk (1999), compuesto por: sistemas políticos, valores e ideologías de los políticos, instituciones en relación a las cuales se articula el discurso, organizaciones políticas, actores políticos involucrados en la definición de discurso, relaciones políticas y procesos políticos.

\subsection{Sistema político}

El discurso de la pobreza dado en el mensaje del 21 de mayo se situó dentro de un sistema que denominamos democrático concertado, en tanto emergió como preocupación de un naciente gobierno democrático post dictadura militar, lo que, a su vez, posibilitó una salida parcial y pactada del poder militar del dominio del Estado.

La superación de la pobreza fue trazada por la CPPD -conglomerado político que llegó a la presidencia en el año 1990 y que estuvo compuesto, en sus inicios, por los partidos que apoyaron la salida condicionada de la dictadura y la primera campaña de 1988 por el No (Godoy 1999) ${ }^{7}$ - como objetivo de Estado. El primer presidente de la esperada democracia -Patricio Aylwin- Azócar provino de este conglomerado, al igual que los siguientes tres mandatarios que gobernaron ininterrumpidamente hasta el año $2010^{8}$.

El pacto que debió alcanzarse con el poder militar para alcanzar la democracia implicó la prevalencia de la constitución política elaborada e impuesta en año 1980 y, con ello, la permisividad a la continuidad de una serie de enclaves autoritarios que consagraron, por más de diez años en democracia, el rol tutelar de las fuerzas armadas y de carabineros sobre

\footnotetext{
Para el año 1990 la Concertación estaba integrada por el Partido Demócrata Cristiano (DC), Partido por la Democracia (PPD) Partido Radical Social Demócrata (PRSD) y Partido Socialista (PS). A estos, originalmente, se sumaban el Partido Democrático de Izquierda (PDI), el MAPU (Movimiento de Acción Popular Unitaria) Obrero Campesino, el Partido Liberal y otros movimientos civiles de los años 80s, hoy todos desaparecidos o fusionados en otros partidos (Godoy 1999).

8 Eduardo Frei R., proveniente, al igual que Patricio Aylwin del Partido Demócrata Cristiano; Ricardo Lagos E., del Partido Por la Democracia (PPD) ;y Michelle Bachelet J, del Partido Socialista.
} 
la institucionalidad constitucional, además de la prevalencia de una serie de normativas que imposibilitaron (algunas medidas hasta la actualidad) la representatividad ciudadana en los órganos del Estado (Fernández 2002) ${ }^{9}$.

\subsection{Instituciones}

En cuanto a las instituciones con las que se articula el discurso de la pobreza presente en los mensajes del 21 de mayo, es principalmente con el Congreso Nacional y con los diferentes organismos gubernamentales destinados a la implementación de las políticas sociales.

Por otra parte, el discurso se articula con el poder militar, en una suerte de gatopardismo, como describe Tomás Moulián (1997), dado que estos cambiaron su ámbito de acción de la dictadura -destinado a la represión políticaal control de la delincuencia y las drogas en democracia. En este contexto, se plantean una particular preocupación por los grupos sociales más pobres de Chile, por lo que habrá una referencia permanente en el discurso del 21 de mayo a las organización castrense en relación a la implementación de políticas de seguridad, como un marco complementario del accionar de las políticas sociales y, por ende, de alianza entre poder civil y militar, en particular en lo que refiere a la intervención de los grupos más pobres de la sociedad chilena en estas materias (Gobierno de Chile 1993).

\footnotetext{
Dentro de los enclaves autoritarios que se mantuvo se encuentran la inamovilidad de los comandantes en jefes y el exorbitante poder civil y militar del Consejo de Seguridad Nacional. Con la Constitución del 80 , también prevaleció la existencia de los Senadores designados, el sistema electoral de carácter binominal, los elevados quórums necesarios para la realización de enmiendas institucionales y la expresa exclusión en la Constitución de cualquier posibilidad de que la población pueda pronunciarse libremente para un cambio constitucional (Fernandez 2002).
}

\subsection{Actores y relaciones}

Desde los primeros mensajes del 21 de mayo se adjudicará al gobierno y sus ministerios como los principales creadores del discurso sobre la necesidad de la superación de la pobreza, especialmente desde las iniciativas generadas a partir del Ministerio de Planificación Nacional, que será enunciado como el principal encargado del diseño de las políticas tendientes a su superación (Gobierno de Chile 1991).

Así, también quedará de manifiesto de modo constante en los mensajes presidenciales la relevancia de las autoridades de la iglesia católica en la definición de la lucha contra la pobreza como problema de gobierno, particularmente aludiéndose a esta como un argumento de autoridad que señala el deber del Estado con los más pobres. Esto quedará de manifiesto en las reiteradas alusiones a este deber, como, por ejemplo, la referencia al papa Juan Pablo II acerca de que "los pobres no pueden esperar", enunciado primeramente por el presidente Aylwin y, posteriormente, por Lagos (Gobierno de Chile 1990).

Por otra parte, desde el II Período analizado en el mensaje se aludirá a los empresarios, organizaciones sociales y dirigentes comunales como actores importante, quienes serán llamados a colaborar en el diseño de las iniciativas para la superación de la pobreza junto a autoridades de gobierno local y eclesiásticas, desde la creación del Consejo Nacional Para la Superación de la Pobreza (CNSP) (Gobierno de Chile 1994), iniciativa que se acotará con el término del Consejo hacia finales del año 1996.

Sin embargo, la relevancia de los empresarios como actores implicados en la construcción 
de la política prevalecerá hasta el 2010, siendo identificados como colaboradores en las tareas destinadas a la superación de la pobreza por medio de la adjudicación de concesiones y privatizaciones de servicios que con anterioridad habían sido administrados por el Estado (Gobierno de Chile 1995). Además, pasaron a ser los principales responsables de dar respuesta ante el desempleo (Gobierno de Chile 2003).

Otros actores involucrados en la construcción del discurso de la pobreza son los organismos multilaterales, quienes comenzaron a tener una gran incidencia en el diseño y evaluación de las políticas sociales para la superación de la pobreza, especialmente desde mediados de los años 90.

Desde finales del I Período analizado se hará referencia en el mensaje a la retroalimentación de Naciones Unidas a las medidas diseñadas para la tarea de superación de la pobreza, por medio de la generación de propuestas como la de Desarrollo Social (Gobierno de Chile 1992) y, más tarde -desde el III Período- a través de la influencia de los lineamientos del Programa de Naciones Unidas Para el Desarrollo (PNUD) por medio de la referencia léxica al Desarrollo Humano como medida de mejora de las condiciones de vida de la población (Gobierno de Chile 2002) ${ }^{10}$.

10 El enfoque de desarrollo humano se basa en la propuesta de Amartya Sen, quien planteó que los ingresos no son un fin, sino un medio que permitiría la realización de capacidades, donde la pobreza revelaría una inadecuada capacidad de transformar medios en fines. En esta línea, el desarrollo humano se comprende como el proceso de ampliación de capacidades de las personas, e implica asumir que el centro de todos los esfuerzos de desarrollo deben ser siempre las personas (MIDEPLAN 2002; Rojas 2007).
Por otra parte, hacia el IV Período -presidido por Michelle Bachelet- habrá una referencia directa a los lineamientos dados desde la Organización para la Cooperación y Desarrollo Económicos (OCDE) en el diseño de las políticas de gobierno, así como la declaración de que Chile es un país líder en superación de la pobreza" (Gobierno de Chile 2007).

\subsection{Procesos}

En relación a los procesos políticos de los que formaron parte los discursos de pobreza presentes en el mensaje del 21 de mayo en el transcurso de estos años, aquellos dados en el marco de las relaciones parlamentarias y gubernamentales dificultaron el quehacer del gobierno para poder desarrollar cambios estructurales a nivel legislativo en algunas áreas que se plantearon como relevantes para obtener mejoras en las situación de vida de la población. La razón de esto es que se trató de una relación mediada por las restricciones institucionales, trazadas desde los enclaves autoritarios.

Uno de los tópicos constantemente referidos en el mensaje, y que se vincula a las condiciones de pobreza en la que se visualizó la tensión mencionada, son las constantes alusiones a las reformas de las políticas laborales ${ }^{11}$.

En esta línea, en el I Período -presidido por Patricio Aylwin- se plantea como uno de los desafíos fundamentales las mejoras en las condiciones laborales, y se sientan las bases para comenzar a generar cambios en la

\footnotetext{
El ámbito laboral fue profundamente mermado en el tiempo de la dictadura, tras la imposición violenta de la ilegalización de los sindicatos y la desregularización de las condiciones laborales, lo que trajo consigo el aumento del poder de los empleadores y una normalización de condiciones laborales inequitativas (Ministerio de Planificación Nacional 1991).
} 
legislación laboral, que permitieran una mejor redistribución de los recursos provenientes del desarrollo de la economía del país, acordándose un reajuste del salario mínimo, tras el "Acuerdo Marco". Sin embargo, posteriormente a este acuerdo y por largo tiempo, se propusieron de manera sucesiva nuevas leyes de reajuste. Al mismo tiempo, se multiplicaban los argumentos por parte de los trabajadores en contra de las reformas en el Congreso (Consejo Nacional para la Superación de la Pobreza 1996), posición ante la cual -dada la escaza capacidad de injerencia de los sindicatos en los diálogos y negociaciones, por el hecho de solo contar con capacidades consultivas- los problemas en este ámbito se mantuvieron sin resolver por un largo tiempo.

En los mensajes presidenciales, desde el II Período se da cuenta de la relevancia de las mejoras de las condiciones laborales y de la postergación de las mismas. Esto se evidencia en la reiteración de tópicos sin resolución en el mensaje año tras año, pasando estos a ser temas pendientes de la agenda presidencial, que reflejaron las diferencias entre los parlamentarios y el gobierno para resolverlas. Lo anterior es explicitado por el ex presidente Ricardo Lagos en su último mensaje del 21 de mayo, en el que se asumen estas diferencias al señalar: "es cierto, hemos trabajado por una mayor justicia en las relaciones laborales y hoy tenemos una Reforma Laboral, no como la hubiéremos querido, pero fue lo más que logramos obtener del Parlamento chileno" (Gobierno de Chile 2005: 9) ${ }^{12}$.

Dentro de esta dinámica, si bien algunos de los grandes temas de la reforma laboral se han legislado después de años de discusiones en el Congreso, esto ha ido de la mano con reiteradas observaciones y modificaciones a los puntos planteados desde el marco de los acuerdos bipartitos (Gobierno- trabajadores o empresarios) o tripartitos. Sin embargo, hasta el 2006 no estaba definido el carácter
Así, el contexto del discurso de la pobreza dado por la CPPD entre 1990 y 2010, se plantea determinado por relaciones de poder en las que la iglesia católica, los organismos internacionales y los empresarios resultaron tener mayor agencia, que los trabajadores -grupo en el que históricamente se han encarnado las necesidades de la población- lo que incidió el modo en que se plasmaron las políticas sociales de los gobiernos.

A continuación se describirán los principales resultados de la investigación acerca de las significaciones de la pobreza, de las acciones para su superación y de los pobres, presentes en el discurso de gobierno durante el período analizado.

\section{La pobreza y las acciones para su superación en el mensaje presidencial del 21 de mayo}

\subsection{Período: "La deuda social"}

En la primera fase de gobierno analizada (19901994), la pobreza en la población se planteó como producto de las políticas implementadas en el período de la dictadura militar, primero por la implementación de una política económica del "derrame"13, que no habría permitido que

vinculante de la participación de los trabajadores en las propuestas para los cambios posibles de la legislación laboral (Morgado 2006), lo cual, sumado a la negativa de acoger las propuestas de los trabajadores, los posicionó constantemente como un grupo contestatario a las propuestas negociadas en el Parlamento.

13 El modelo neoliberal del régimen militar tuvo dos componentes principales. Uno de ellos fue su objetivo de maximización del crecimiento económico y todo el resto eran un subproducto, por lo cual los problemas sociales y distributivos se resolvían gracias al "chorreo" (trickle-down) de los recursos provenientes por este medio, por lo que el rol del Estado se restringía a la implementación de políticas asistenciales para los más pobres (Garretón 2013). 
los recursos provenientes del crecimiento económico del país se distribuyeran de manera equitativa en la sociedad, generado a su vez profundas desigualdades de acceso entre los distintos grupos sociales (Gobierno de Chile 1990); y segundo, por una serie de políticas públicas que tendieron a la reducción del aparato del Estado y conllevaron a un deterioro de los servicios sociales:

\begin{abstract}
"Los últimos dieciséis años han significado un serio retroceso en la situación de los más pobres. En cada recesión, los sectores de menores ingresos sufrieron la desocupación y la caída de sus remuneraciones (...), como asimismo los efectos de un drástico deterioro en el apoyo estatal a los programas sociales" (Gobierno de Chile 1990:46).
\end{abstract}

En este período se declaró que era la inequidad de acceso a los recursos provenientes del crecimiento económico lo que mantenía al país en condiciones de pobreza, asociándose su significación a la carencia de recursos económicos y planteándose su prevalencia como un riesgo que podría generar escenarios de conflicto y división social, afectando la estabilidad política y económica de país:

\footnotetext{
"Una sociedad atravesada por desigualdades socioeconómicas inaceptables para el sentimiento moral contemporáneo es el mejor sustrato para la exacerbación del conflicto político y su desenlace: el quiebre institucional y la opresión política consiguiente (...) con el consiguiente resultado de inestabilidad y estancamiento económico" (Gobierno de Chile 1990: 28).
}

Tras esta idea, se definieron las acciones para la superación de la pobreza por parte del gobierno como "el pago de la deuda social contraída con los más pobres" (Gobierno de Chile 1990: 41), declarándose la labor del Estado como reparadora y restablecedora de las condiciones laborales de estos grupos por medio de la declaración del Acuerdo Marco (Gobierno de Chile 1990) y la implementación de nuevos programas sociales destinados a lo que se denominará el "enfrentamiento de la pobreza" (Gobierno de Chile 1990: 47).

\subsection{Período: "La modernización del país"}

En el segundo período analizado, presidido por Eduardo Frei Ruiz-Tagle, el discurso acerca de la necesidad de la superación de la pobreza deja atrás su vinculación a una deuda social con los más pobres. La pobreza fue planteada como un problema social limitante para el progreso nacional, argumento tras el cual se declaró como fundamental por parte del Estado la estimulación del crecimiento económico del país en su conjunto.

Además, la estabilidad social ya no es propuesta como el resultado de una mayor equidad tras el enfrentamiento de la pobreza, sino que se declara como condición necesaria para el crecimiento económico, donde la superación de la pobreza iría de la mano con el crecimiento. En palabras del presidente de la época: "todos los chilenos deben saber que la estabilidad política es una indispensable condición para el crecimiento económico. Todos, especialmente los más pobres, deben saber de qué manera el desarrollo social depende del crecimiento económico" (Gobierno de Chile 1994: 53).

De la misma forma, en este período la pobreza se declara como un problema que comporta dos ámbitos. Por un lado, se plantea como fruto de una infraestructura deficitaria de país que dificultaría el desarrollo económico (Gobierno de Chile 1995). Por otro lado, se define como una característica de una parte de la población -los pobres- que presentaría carencias a nivel 
de oportunidades y capacidades de acceso al desarrollo económico. Así, son identificados como grupos en condiciones de desprotección o vulnerabilidad.

En cuanto a la superación de la pobreza como falencia de infraestructura de país, se declarará un cambio de estrategia de crecimiento económico, denominado "proceso de modernización del país" (Gobierno de Chile 1995), el que implicó prácticas desde las que se argumentó la necesidad de incorporar la inversión de empresarios privados para el logro de los objetivos de desarrollo.

La acción de los empresarios será descrita como un apoyo a la acción del Estado, por medio de su gestión desde la privatización de servicios sociales y entrega de concesiones para implementar la infraestructura para el desarrollo. Planteándose. Esto se evidencia en las palabras del ex presidente Eduardo Frei: “...lo que importa no es quién realiza la inversión, sino de qué manera resolvemos los problemas concretos y cotidianos de la gente, cuidando siempre los intereses de los usuarios y concretamente de los más pobres" (Gobierno de Chile 1995: 18).

Por su parte, en cuanto a la superación de la pobreza como problema específico de los identificados como pobres, estos últimos son definidos como grupos que están situados en territorios determinados del país, tratándose de aquellas zonas con mayores índices de pobreza (según el mapa de la pobreza que utiliza el gobierno para la focalización de sus acciones), y es hacia ellos que se declararán acciones desde las políticas sociales, destinadas a una mejor gestión e implementación de los servicios sociales:

\begin{abstract}
"Hemos diseñado un programa de acción territorial que se ha iniciado en las 71 comunas más pobres del país, y hemos definido los cinco grupos sociales más desprotegidos: Los niños, las mujeres jefas de hogar, los adultos mayores, los discapacitados y los pueblos indígenas" (Gobierno de Chile 1995: 22).
\end{abstract}

Así también, los conocimientos explicitados por el gobierno acerca de las vías para la superación de la pobreza en este período se alinean con marcos mundializados en relación al fenómeno, elaborados principalmente desde la Organización de Naciones Unidas (ONU) y desde el Centro de Estudios para América Latina y el Caribe (CEPAL). Lo anterior fue implementado, en particular, con la incorporación de los planteamientos del Capital Social ${ }^{14}$, en base al cual la pobreza se esboza como fruto de una carencia de oportunidades y redes de acción colectiva, donde se supone la noción de recursos (o activos) individuales y comunitarios que permiten ampliar las posibilidades de mejora de condiciones de vida $y$, desde ello, superar la pobreza.

En la base del Capital Social se conjugan factores de voluntad y capacidades individuales y colectivas de los identificados en condición de carencia, por una parte, y de mejora desde marcos de posibilidades institucionales (o de protección) brindadas por el Estado para la realización de las mismas, por otra (Ministerio de Planificación Nacional 2002).

A su vez, en el discurso se plantea la relevancia del círculo virtuoso dado entre educación

\footnotetext{
Si bien esta teoría tiene múltiples desarrollos y la base de la propuesta se atribuye a la ONU, esta proviene, principalmente, de los enfoque de James Coleman (Coleman 1990), en sociología de la educación, y de Robert Putnam (1993), en ciencias políticas. La relevancia del Capital Social para los individuos y grupos que lo poseen es la potencialidad que otorga de obtener beneficios a partir del aprovechamiento de redes sociales y de los capitales potenciales, tanto individuales como colectivos. Chile fue uno de los organizadores de la Cumbre de Desarrollo Social de 1994.
} 
y desarrollo económico como base para la superación de la pobreza (Perla 2007), el cual permea el enfoque de las políticas educativas y las acciones orientadas hacia la reforma educacional básica. Allí primó la idea de que la educación es una herramienta de progreso,, de oportunidades para las familias pobres y de ascenso social, desde la adquisición de nuevos conocimientos que les permitan resolver eficazmente situaciones complejas, proceso que además se plantea como esencial para el logro del desarrollo de país (Gobierno de Chile 1994).

Ambos marcos explicativos -el de Capital Social y el círculo virtuoso de la educación- se articulan con visiones desarrollistas del crecimiento económico, que resultaron funcionales para vincular la idea de bienestar social a la de progreso económico del país, desde el aprovechamiento por parte de la población de "oportunidades" brindadas por el Estado y la sociedad en su conjunto.

En esta línea, en este período se plantea una superación de la pobreza que depende de las voluntades y capacidades de los identificados como pobres, postura reflejada en la gestión de proyectos comunitarios como el "Pavimento Participativo" (Gobierno de Chile 1996) y el incremento de créditos y becas de estudio escolar y universitarias solo para aquellos alumnos en condición de pobreza que presentaban excelencia académica (Gobierno de Chile 1996).

De este modo, si en el primer período la preocupación por la pobreza se plantea tras la mejora en las condiciones laborales y de vida de la población -comprendidos los pobres como población en carencia debido a situaciones promovidas en dictadura- desde el gobierno presidido por Eduardo Frei R. se enfatizará en la mejora de infraestructura productiva y capacidades humanas de los más pobres como centro de las posibilidad de superación de la carencia y, por ende, como herramienta fundamental para el desarrollo del país. Sin embargo, el desarrollo de capacidades en el marco del Capital Social se focalizó en la acción directa en las comunidades, no atribuyendo esta capacidad de agencia como necesaria en el ámbito de las condiciones laborales, pasando la intervención en las condiciones laborales de quienes carecían de recursos y la relevancia de los espacios de acuerdo entre empresarios y trabajadores a un segundo plano en el discurso de la pobreza.

\subsection{Período: "La lucha contra la pobreza dura"}

Por otra parte, en el transcurso del III Período analizado, el entonces presidente Ricardo Lagos, al tratar la pobreza como problema de Estado en el discurso del 21 de mayo, se refirió principalmente a problemas de los identificados como pobres, declarándose en esta materia una nueva focalización de las prácticas hacia grupos sociales en extrema pobreza, lo que se declara como la lucha contra la "pobreza dura".

La pobreza dura se plantea como necesaria de ser abordada desde el Estado, asumiéndose como la única forma de pobreza que no se supera tras las iniciativas que tienden a vincular a estos grupos y su bienestar social al desarrollo económico del país, considerados en el período anterior:

"Hemos aprendido que el camino más eficiente para
combatir la pobreza, es el crecimiento económico
acelerado. Pero al mismo tiempo hemos aprendido que hay una proporción de nuestra pobreza que no puede ser 
superada por el simple impulso al crecimiento. Ese sector es el que llamamos "el de pobreza dura" (Gobierno de Chile 2002: 30)

El gobierno circunscribirá su deber en cuanto a la superación de la pobreza desde las políticas focalizadas en los grupos de extrema pobreza, línea tras la cual declarará nuevas acciones, como la creación del Programa Chile Solidario (Gobierno de Chile 2002).

De la misma forma, se referirá a la superación de la pobreza de los demás grupos sociales como fruto del desarrollo humano y de las posibilidades que brinda el círculo virtuoso de la educación -como fue planteado desde el periodo anterior- y nuevamente en relación a la agencia individual de quienes se encuentran en condiciones de carencia:

\footnotetext{
"Las medidas que hemos decidido para combatir la extrema pobreza, deben ser de efecto inmediato para nuestros conciudadanos que están hoy en las peores condiciones. La creación de una sociedad verdaderamente más justa y sin pobreza, será el fruto de esfuerzos sostenidos, en cuyo centro estará un fuerte impulso a la educación y el conocimiento" (Gobierno de Chile 2002: 34)
}

Contextualmente, el énfasis de la labor del Estado en la lucha contra la extrema pobreza resultó ser una estrategia que respondió a las prioridades determinadas desde el Estado chileno para el logro de los objetivos del milenio contenidos en el marco de la ONU, donde se definió la superación de la pobreza como objetivo principal a lograr por las naciones hacia el 2015, en función del desarrollo humano (Ministerio de Planificación Nacional 2002).

Los conocimientos explicitados acerca de los extremos pobres desvelan, desde el mensaje presidencial, que las acciones diseñadas para el enfrentamiento de la extrema pobreza se basaron, principalmente, en los enfoques de vulnerabilidad y de derechos ${ }^{15}$, formando parte de los discursos de saber acerca de los pobres al momento de identificarlos como grupos necesitados, enfatizándose su desprotección de derechos y condición de riesgo (Gobierno de Chile 2002).

Desde estos nuevos marcos, adquirirá énfasis la referencia al "progreso social" como indicador de superación de pobreza (Gobierno de Chile 2004). Desde los conocimientos explicitados, el "progreso social" implicará la mejora en la calidad de vida de la población más pobre, fundamentalmente desde las políticas sociales implementadas por el Estado a través de los programas sociales, donde se determinó como objetivo fundamental la promoción de derechos mínimos para la vida en esta población (Gobierno de Chile 2003).

La implementación del Programa Chile Solidario reflejó los lineamientos enunciados (Gobierno de Chile 2003), particularmente en la aplicación del Programa Puente, el que se basó en el análisis

15 En relación al enfoque de vulnerabilidad, el gobierno de Chile se guió, en este período, principalmente por los planteamientos sobre la materia de Filgueira (2001) y Kaztman (2000), para quienes la vulnerabilidad se consideró como el riesgo de un individuo, hogar o comunidad de ser heridos o dañados, donde su grado en relación a la pobreza es comprendida como resultado de la relación entre la disponibilidad y la capacidad de movilización de activos, expresada como atributo individual o de los hogares y la estructura de oportunidades dentro de la sociedad (Ministerio de Planificación Nacional 2002). Además, desde el enfoque de derechos se asumió que las situaciones de pobreza se encuentran determinadas por temas no sólo vinculados a los recursos económicos, sino que también relacionados con prácticas culturales, políticas y jurídicas que facilitan o promueven la discriminación contra ciertos individuos o grupos, como las mujeres, los indígenas, las minorías étnicas; actuando como mecanismos de exclusión y contribuyendo a generar pobreza (Abramovich 2006). De este modo, mientras desde la vulnerabilidad se establece una condición de los sujetos, desde el enfoque de derechos se determina una función del Estado de velar por la protección de derechos y promoción de medios para el desarrollo de la población, siendo ambos enfoques complementarios en cuanto a su aplicación. 
de la vulnerabilidad social, desde una matriz de riesgo social, para definir cuál era el riesgo principal al que se enfrentan las familias de extrema pobreza, las condiciones mínimas para evitarlo y los factores protectores que permiten asegurar dichas condiciones por medio del desarrollo de capacidades definidas como fundamentales (Serrano y Raczynski 2004).

Este programa abordó el tratamiento de los derechos sociales, instalando el concepto de "mínimo" asociados a la idea de derechos mínimos de sobrevivencia, comprometiéndose la política social a alcanzar unos umbrales de satisfacción básicos para la superación de la extrema pobreza en los grupos sociales en condiciones de carencia (Serrano 2005) ${ }^{16}$.

La focalización del discurso del Estado de superación de la pobreza no incorporó una reflexión acerca de la necesidad de intervenir en condiciones de vulnerabilidad básica no vinculadas directamente con el entorno inmediato o con las capacidades de agencia de los identificados como pobres. En esta línea, en relación al contexto de producción del discurso, no involucró un cuestionamiento acerca de las condiciones laborales y su relación con las condiciones de pobreza de la población, omitiendo así los mensajes presidenciales la relación entre pobreza e inequidad existente en este ámbito, pese a que uno de los grandes problemas de los identificados como pobres era la cesantía (en un $57,6 \%$ de los hogares en

16 Tras estos principios, la práctica del programa incluyó una intervención en el conjunto de miembros de las familias a lo largo de su ciclo de vida, donde las condiciones de vulnerabilidad se midieron de acuerdo a diversos factores no necesariamente relativos a la obtención directa de recursos económicos del sistema, aunque si se plantearán estos como relevantes para la mejora de las condiciones de vida y la superación de la pobreza (Serrano 2005). situación de extrema pobreza y en un $78,8 \%$ de las familias identificadas como pobres, quienes tenían algún miembro activo laboralmente en este periodo) (Solimano y Pollack 2006).

De manera similar, no se contempló dentro de los ámbitos de acción de las políticas contra la pobreza una intervención en las condiciones laborales del sector informal, área en la que se desempeñaban mayoritariamente quienes vivenciaban condiciones de pobreza. En dicho escenario, sólo el 50\% tenía contrato de trabajo y un $35 \%$ accedía efectivamente a la seguridad social, además de que estos trabajadores recibían salarios más bajos y trabajan más horas en comparación con los trabajadores del sector formal (Solimano y Pollack).

La centralidad en la mejora de las condiciones de vida por medio de las políticas sociales destinadas al progreso social posibilitó la disociación del discurso del enfrentamiento de la pobreza del referente a la mejora de las condiciones laborales y, con ello, de la mejora en las condiciones de inequidad en la distribución de recursos por la vía laboral, situación que se declara explícitamente en el discurso, pese a la mejora en cuanto a indicadores de superación de pobreza que tenderá a incrementarse hasta nuestros días: ${ }^{17}$

\footnotetext{
"Pero reconozcámoslo: Chile sufre de una crónica desigualdad en la distribución de los ingresos provenientes del trabajo. La diferencia de ingresos entre el 20 por ciento más rico y el 20 por ciento más pobre es del orden de catorce veces. Esta distribución ha variado muy poco en los últimos 14 años" (Gobierno de Chile 2005: 8)
}

En la actualidad existe en Chile una concentración de la riqueza en cuanto a ingresos que se ha incrementado posteriormente al primer gobierno de Michelle Bachelet (2006-2010), donde la diferencia entre quienes ganan más y los que ganan menos es 17 veces un salario promedio, y el $1 \%$ de la población concentra el $30 \%$ de la riqueza del país (López, Figueroa y Gutiérrez 2013). 


\subsection{Período: "La acción hacia los más vulnerables"}

En el IV Período se declarará, en el mensaje presidencial del año 2006, el problema de la pobreza en Chile, en gran parte, como superado. Este discurso fue respaldado, como se mencionó al inicio del presente artículo, por los indicadores de la OCDE (Gobierno de Chile 2007).

En este contexto, Michelle Bachelet propondrá en su programa de gobierno para este período la necesidad de asumir como Estado una nueva etapa de intervención social, liderada por lo que denominó el Sistema de Protección Social ${ }^{18}$ (Bachelet 2005). Desde él, el Estado se propone como objetivo consolidar una de protector social, por medio de asumir el enfoque de vulnerabilidad y derechos ya no solo como un modo de comprender las situaciones de pobreza extrema, sino que de comprensión de la población en general y de regulación del rol de protección del Estado hacia esta:

"Un logro central en estos dos años ha sido instalar el sistema de protección social como verdadero objetivo nacional. Nuestro propósito ha sido sentar las bases de un Estado social y democrático de derecho, que abandona el asistencialismo de las políticas sociales y que asume el enfoque de derechos de las personas" (Gobierno de Chile, 2008: 19).

Además, dentro de las prácticas se anuncia la modificación del sistema de focalización de beneficiarios de programas sociales,

8 La creación del Sistema de Protección Social se conformó por un conjunto de políticas y programas destinados a reducir la vulnerabilidad en la población, agrupando en sí la mayor parte de los programas existentes de educación, vivienda, seguridad social (programas de pensiones, seguros de desempleo), subsidios monetarios, atención en salud, protección y acceso a derechos. Todos esos ámbitos iban en la línea de la clasificación del gasto social dada por la OCDE (Herrera, Larrañaga y Telias 2010). transformando la ficha CAS-2 en la Ficha de Protección Social (FPS) (Gobierno de Chile 2006), cambiando el enfoque de carencias -asociado a pobreza absoluta y que primaba desde su creación durante la dictadura militarpor uno orientada a medir la vulnerabilidad de condiciones socioeconómicas. La FPS será utilizada para la focalización del SPS ${ }^{19}$.

Tras estas modificaciones se articuló un cambio en la definición de las problemáticas sociales, pasando de un enfoque que focalizaba los programas sociales según indicadores de carencia de recursos materiales, diferenciados según la condición de no pobre, pobre y extremo pobre (ámbito predominante por más de 15 años), a otro que focaliza las acciones desde un marco de diferenciación entre vulnerables y no vulnerables.

Si en el período anterior el concepto de vulnerable era utilizado en los mensajes del 21 de mayo a modo de sinónimo de pobre, en los mensajes emitidos en esta fase se diversificará el grupo objetivo de las políticas sociales, enunciándose los pobres como un grupo más dentro de los identificados como vulnerables y al Estado en una función protectora de estos:

\footnotetext{
"El Chile cohesionado que queremos construir también pasa por reconocer que hay muchas otras desigualdades y exclusiones de las que tenemos que hacernos cargo: la discriminación que sufren los discapacitados, los inmigrantes, las minorías sexuales, los más pobres, los más viejos. Muchas veces, producto de nuestros prejuicios, el país desperdicia el talento de tantas personas" (Gobierno de Chile 2006: 16).
}

19 En la FPS se establecieron indicadores de vulnerabilidad y, desde ello, de derechos a acceso a programas. No se condicionará la intervención gubernamental a la prevalencia de una condición de pobreza, sino que más bien a las variables de riesgo de exposición a situaciones de vulnerabilidad en ámbitos de derechos acceso a servicios, etc. (Herrera et al. 2010). 
El gobierno asumió el deber público de asegurar el acceso a oportunidades de los vulnerables y de estimular su esfuerzo. Su rol protector involucró prácticas en relación al trabajo, la salud, la educación, el transporte, etc., constituyendo acciones declaradas en función de asegurar y cubrir riesgos de la población (Gobierno de Chile 2006).

Sin embargo, tras la nueva orientación de la política social, la pobreza desde el enfoque de derechos seguirá planteándose en consonancia con los parámetros internacionales como "la violación más abyecta de derechos humanos" (Ministerio de Planificación Nacional 2002: 37). En esta línea, en los mensajes del 21 de mayo se prestará especial atención a los más pobres, refiriéndose al fenómeno de la pobreza metafóricamente, aludiendo a esta con la expresión "como un resfriado" (Gobierno de Chile, 2006: 20). De esa forma, prevalecerá un discurso de saber acerca de ésta como determinada por circunstancias que escapan al control humano, reflejado en la idea de enfermedad, dejando al margen la identificación de las responsabilidades de los distintos actores sociales en la prevalencia de situación de carencia.

La creación del SPS referido en el discurso y de la FPS constituyeron la puesta en práctica de tecnologías de Estado que respondieron a la incorporación de nuevos discursos de verdad acerca de los problemas sociales. Desde ellos que se enfatiza la función del Estado, ampliándose la comprensión de lo que hasta el momento se había comprendido como labores de seguridad circunscritas a la defensa frente al terrorismo y la delincuencia, a las que se agregaron las prácticas dadas desde las políticas sociales.
De este modo, en el discurso presidencial se reforzó la imagen de un Estado protector, a la vez que se refería a dos dimensiones de la pobreza: por una parte, a la pobreza la de los pobres ahora como vulnerables y, por otra, a la pobreza como problema de país, reforzándose la idea de ser un problema en gran medida superado.

Al mismo tiempo, se declara como fundamental dentro de las tareas del Estado el continuar incentivando el crecimiento económico, entendido como la base para el desarrollo y como preocupación permanente del Estado (Gobierno de Chile 2008). Las referencias a la pobreza no quedaron al margen de este discurso de desarrollo del país, puesto que los pobres se valorizan, en conjunto con los demás grupos vulnerables, como "desperdicio de talentos" (Gobierno de Chile, 2006, p. 16).

En esta lógica, en el discurso se enunció de modo declarativo la necesidad de que los chilenos se vuelvan más productivos, por medio de la creación de nuevos tipos de productos que incorporaran saberes abstractos que permitirían la creación de tecnologías y nuevos conocimiento científicos (Gobierno de Chile 2006). Estos últimos se proponen como productos de consumo centrales para el desarrollo económico de país, ya que brindan dominio acerca de la información e innovación (Gobierno de Chile 2008).

En continuidad con los períodos anteriores, la educación fue una herramienta enfatizada en el discurso como medio de formación, planteándose en el 2007 que "una mejor educación debe ser nuestra gran apuesta de futuro como país. Es el desafío de toda nación moderna, que aspira a integrarse a la sociedad 
globalizada del conocimiento" (Gobierno de Chile 2007: 7). La educación superior se declarará como un medio de movilidad social de la mano del desarrollo de capacidades cognitivas de los individuos, entendidas como herramientas para ascender socialmente desde sus propios conocimientos, esfuerzo y mérito (Gobierno de Chile 2006). En esta línea se declarará Nacciones de incremento de becas de estudio y de gastos de manutención (Gobierno de Chile 2006) ${ }^{20}$.

A su vez, cabe destacar el énfasis que adquiere en los discursos del 21 de mayo la intervención del Estado en la educación de la primera infancia, como medio para hacer frente a la inequidad y a la exclusión social, declarándola como necesaria "porque es en esos primeros años donde se gestan las primeras exclusiones y desigualdades" (Gobierno de Chile 2006: 4). Las acciones en este sentido se argumentaron en una serie de trabajos de investigación que respaldaron la idea de que la educación desde la primera infancia desactivaría las causas de la pobreza, así como sus canales de transmisión entre generaciones (FOSUPO 2006).

Como parte de las acciones educativas en la primera infancia, se propuso una intervención en la educación escolar y una práctica directa en la relación educativa entre los niños y niñas en el entorno familiar. Es en este marco que se declara la creación del Programa Chile Crece Contigo (ChCC), el cual se propuso como

Esta declaración en el discurso presidencial se realiza en un contexto marcado por las manifestaciones estudiantiles que demandaban, entre otros puntos, la reforma de la Ley Orgánica Constitucional de Educación (LOCE) y la modificación de la Jornada Escolar Completa (JEC), por no percibirse socialmente una mejora considerable en la calidad de la educación, ni un progreso en la "igualdad de oportunidades del modelo educativo chileno (Bellei, Contreras y Valenzuela 2010; Torres 2010). medio para estimular el desarrollo cognitivo y emocional de los niños y niñas, incorporando este desarrollo como fundamental para un posterior buen desempeño social (Gobierno de Chile 2009). De este modo, se definió como un objetivo de Estado la intervención educativa focalizada en la infancia, explícitamente referida a los niños y niñas más vulnerables:

\footnotetext{
"En los próximos cuatro años implantaremos un sistema de atención preescolar para niños de entre uno y tres años que entregará atención a todos los niños de hogares pertenecientes al 40 por ciento más pobre de la población. Nuestra meta es universalizar el kínder y el pre kínder" (Gobierno de Chile 2006: 4)
}

Las acciones desarrolladas con la infancia y a nivel de educación formal fueron caracterizadas por la Presidenta como perfeccionamiento del capital humano y como un estímulo al desarrollo de la nación (Gobierno de Chile2007). De la misma forma, desde esta orientación se validó no tan solo la intervención en la educación escolar, sino que también en el campo de las familias, cuidado de los niños y, particularmente, en el vínculo entre la madre-hijo(a) en los primeros años, como se propuso desde el programa ChCC.

De este modo, desde las racionalidades de gobierno se comprenderá a los niños y niñas de las familias pobres como sujetos modelables y perfectibles desde su desarrollo temprano, mediante la acumulación de capacidades, donde sus capacidades biológicas potenciales serían parte de la herramienta propuesta para incrementar sus recursos en el futuro y así lograr la superación.

La relevancia del capital humano para el desarrollo, en confluencia con la superación de la pobreza mediante la educación, evoca planteamientos presentes ya en los años 50 en la teoría económica (Thaylor 1998). Estos 
fueron incorporados en los períodos anteriores analizados, tras la relevancia del círculo virtuoso de la educación para el desarrollo, aludiéndose implícitamente en el discurso de la pobreza a la educación como salvadora de las inequidades. Además, esto se revela en la definición como determinante de la situación, la carencia de capacidades y conocimiento del "pobre", y omitiendo las referencias a los factores estructurales que median en el mantenimiento de la inequidad en cuanto a educación.

Sin embargo, la novedad del discurso de la presidenta Bachelet se encuentra en el campo de formación del capital humano actual, reenfocándose la función del Estado. La acción focalizada en los grupos más vulnerables y la intervención para la generación de nuevos capitales relevó la importancia de la subjetividad de los individuos en la formación en función del capital. Ya no sólo el hacer y el saber de los trabajadores/as son importantes, sino que también su disposición intelectual y afectiva desarrolladas desde la primera infancia, en lo que su desarrollo emocional y las experiencias vitales son considerados factores productivos tan o más importantes que el cuerpo.

En este discurso también se consolida una relación entre capital humano y logro de equidad, siendo la equidad se planteada como posible de lograr desde una acción focalizada del Estado en los grupos más vulnerables (especialmente en la infancia), a fin de contrarrestar -mediante una condición de derechos- su situación de vulnerabilidad y, de la mano de su futuro mérito educativo, la posibilidad de la movilidad social en función del logro de la equidad.

De este modo, el discurso de gobierno se centra en la acción focalizada en los vulnerables, por medio de la protección y promoción de derechos, dejando de lado un deber del Estado vinculado a la reorganización de la estructura social chilena. En lugar de eso, se focaliza en un discurso que se enfoca en reducir las desigualdades en cuanto a posiciones sociales, desde una reducción de la desigualdad de oportunidades, planteándose la búsqueda de la reducción de las discriminaciones que impedirían la movilidad social en función de los méritos personales (Dubet 2012) ${ }^{21}$.

\section{Acerca del pobre en el mensaje presidencial del 21 de mayo}

A lo largo de los 20 años analizados los gobiernos comprendieron como pobres a diferentes grupos de sujetos, que tenían como común denominador una condición de carencia, de acuerdo a los sistemas de medida absolutos con los que se midió el fenómeno. En este sentido, se identificó como pobres, principalmente, a mujeres, niños, campesinos, jóvenes, adultos mayores, indígenas y discapacitados.

En este sentido, en relación a cómo se comprende al pobre en el mensaje presidencial, se identificó una serie de atribuciones adjudicadas a ellos en el discurso, correspondiendo algunas de ellas a los diferentes períodos analizados en particular. Sin embargo, también se hallaron ciertas atribuciones que resultaron transversales a lo largo de los 20 años analizados. En este sentido, desde los valores experienciales y

\footnotetext{
Si desde la igualdad de oportunidades se plantea que las hijas de los obreros tengan las mismas oportunidades de llegar a ser profesional que las hijas de un banquero, en el enfoque de posiciones se trata mayormente de reducir la brecha en las condiciones de vida y trabajo entre obrero y el banquero, más que prometerle a la hija del obrero mejores oportunidades (Dubet 2012).
} 
relacionales del léxico se pudieron identificar una serie de atribuciones comunes a los pobres para los diferentes períodos. Estas fueron:

a. Su improductividad. Los pobres fueron identificados continuamente como sujetos sin capacidades para generar recursos dentro del sistema económico, ya sea por carencias físicas, cognitivas, tecnologías $\mathrm{y} / \mathrm{o}$ financieras. Su improductividad se planteó como determinante de su carencia de ingresos. Sin embargo, no cualquier recurso se definió como factor de productividad, sino solo aquellos que podían constituirse como tal en el sistema económico y que habían de adquirir los pobres para superar su condición.

En esta línea, la idea de productividad se vinculó en mayor medida a capacidades en el ámbito laboral. En el primer y segundo período analizado se referirán a la necesidad del impulso de pequeños productores (artesanos, pescadores, agricultores, etc.), ámbito en el que se desarrollarán las iniciativas de fomento productivo (Gobierno de Chile 1994) $\mathrm{y}$, posteriormente, la relevancia que adquirirán la educación escolar y universitaria para el incremento de la productividad.

Esta racionalidad acerca de la productividad se respaldó, primeramente, en el enfoque de capital social (Ministerio de Planificación Nacional 2002), desde el cual la carencia de recursos se denominó como falta de activos en relación a las oportunidades del sistema económico:

"Se baten solos, como pueden, con medios y recursos más o menos primitivos. Se trata de impulsar una política de apoyo efectivo a estos pequeños productores, la que, sobre la base de su participación e iniciativa, les permita modernizarse y lograr niveles crecientes de productividad e ingresos" (Gobierno de Chile 1992). b. Carente de saberes. Esto no se referirá exclusivamente a conocimientos técnicos o vinculados al trabajo como factor productivo. El pobre "no sabe" los conocimientos necesarios tanto para llevar una buena calidad de vida, como para integrarse positivamente en el sistema económico, características directamente proporcionales a su grado de pobreza. En el caso de los extremos pobres, estos tendrían un déficit de saberes mínimos para una vida digna, comprendido como no saber acceder a los servicios sociales, ni demandar derechos.

En esta línea, desde el primer período se planteó la carencia de saberes de los pobres, especialmente en el ámbito laboral, así como también se señaló a los niños y jóvenes en condiciones de pobreza, principalmente, como quienes han de desarrollar sus saberes como posibilidad para la movilidad social. Hacia el tercer período analizado se plantea no sólo la carencia de saberes para la inserción laboral, sino también de habilidades, particularmente de las mujeres en condición de pobreza para administrar la institución familiar y estimular a los niños desde su rol de cuidadoras.

La racionalidad acerca del conocimiento así propuesto, se relacionó con los planteamientos provenientes de los enfoques de capital humano, vulnerabilidad y derechos, que en conjunto proponen 'el saber' como fundamental para la superación de la pobreza, base del capital humano y elemento necesario de potenciar la movilidad social, comprendiéndose como saber aquel que resulte ser un activo para la integración al desarrollo:

\footnotetext{
“...no saben de subsidios únicos, no saben de subsidios a las cuentas de agua potable, no saben de pensiones asistenciales, no saben de becas de retención, no saben de programas de salud, no saben de cursos de capacitación"(Gobierno de Chile 2002).
} 
c. Usuarios de servicios públicos. Desde el gobierno se comprendió que la inversión y mejora de los servicios públicos constituye un aporte a la mejor calidad de vida de los pobres. Por lo tanto, los servicios públicos de salud, vivienda y educación se describen como instancias donde acuden principalmente aquellos sin capacidad de pago dentro del mercado, respondiendo tras esta lógica a una idea de pobre centrada en necesidades básicas insatisfechas.

En esta lógica, los gobiernos de la CPPD invirtieron y mejoraron la calidad y cobertura de los mismos en función de la mejora de la calidad de vida de los más pobres, de acuerdo a una racionalidad de gobierno donde no existe la provisión de servicios universales, idealizándose la calidad del servicio privado como ideario a imitar desde el servicio público. De este modo, la racionalidad de gobierno transformó los servicios públicos en servicios para sujetos en condición de pobreza, estimulando la mejora de estos desde una acción focalizada en los pobres y propiciando que las familias de menores recursos continuaran viviendo agrupadas, atendiéndose en hospitales -en contraposición a las clínicas particulares- y educándose en liceos públicos o particulares-subvencionados, a diferencia de los ciudadanos con mayor poder adquisitivo:

El Estado tiene la tarea irrenunciable de asegurar servicios básicos para la Población (...) Consideramos que éste es un tema eminentemente práctico, en donde lo que importa no es quién realiza la inversión, sino de qué manera resolvemos los problemas concretos y cotidianos de la gente, cuidando siempre los intereses de los usuarios y concretamente de los más pobres (Gobierno de Chile 1995: 18).

d. Son a-políticos: Desde las prácticas sociales en relación a los pobres descritas en el mensaje del 21 de mayo, el discurso de gobierno atribuye la principal agencia al Estado, como órgano que detenta el saber sobre la situación de vida del pobre y el modo de superación de su pobreza. Al mismo tiempo, se caracteriza a los pobres como carentes de saberes y recursos e incapacidades para demandar derechos, definiéndolos como beneficiarios de las políticas sociales (Gobierno de Chile 2003). En este sentido, se omite la referencia a los pobres como gestores con capacidad de incidencia en el diseño de las políticas sociales, o como sujetos con conciencia crítica sobre su situación de vida. Esto, pese a presentarse en los diferentes períodos analizados situaciones de malestar social y de demandas -por parte de la población- de cambios en las práctica referentes al accionar de la políticas sociales, especialmente en los problemas referentes al ámbito laboral (Frías 2008; Ramírez 2001) y educacional ${ }^{22}$ (Jackson 2013). Además, existieron confrontaciones directas y negación a ser intervenidos, como fue el caso del pueblo mapuche ante las acciones del Programa Chile Solidario (lbarra y Martner 2006), situaciones que no son referidas directamente en el discurso o son atribuidas a grupos diferenciados a los de los pobres, negando así sus capacidades como sujetos políticos ${ }^{23}$ y como actores contraparte de la creación de las acciones, obstaculizando así la posibilidad de diálogo con estos desde

22 El financiamiento de la educación superior fue un problema en el período analizado, que generó profundo malestar en la población estudiantil, entre otros motivos porque por cada peso que aporta el Estado, las familias tienen que otorgar cinco, y el costo de tener un estudiante en la universidad llegó a superar el ingreso familiar del $60 \%$ de la población (Meller 2011; Jackson 2013).

23 Según Isabel Rauber (2003), cinco elementos parecieran conformar el proceso de constitución del sujeto político: 1) conciencia crítica de la función que asigna el sistema; 2) una voluntad de cambio y asumirse parte de un colectivo que comparte dicha voluntad de cambio; 3) la capacidad para reinterpretar y resignificar dicha realidad; 5) la formulación de un proyecto; y 6) la acción social con la intencionalidad de transformar dicha realidad. 
la validación de su capacidad reflexiva sobre la práctica social del Estado.

\section{Consideraciones finales}

Primeramente, cabe destacar que en el transcurso de los 20 años de gobierno de la CPPD, las políticas sociales orientadas a la superación de la pobreza permitieron una estrategización constante de las prácticas del Estado hacia la población, orientadas principalmente a la inclusión de los identificados como pobres al proyecto de desarrollo del país, y siendo este el grupo social prioritario de la política social, especialmente en los primeros quince años de gobierno. Sin embargo, los gobiernos de la CPPD establecen una continuidad básica con el periodo de la dictadura militar, al conservar los sistemas de medida, predominando, pese a la incorporación de nuevos enfoques a la comprensión del fenómeno, los enfoque absolutos de pobreza al momento de identificar a la población beneficiaria de la política social, no recuperando la población su capacidad de incidencia en el diseño y gestión de la política social destinada al enfrentamiento de la pobreza.

La intervención en la lucha contra la pobreza se configuró como un proceso desarrollado desde aquellas prácticas de las políticas sociales al inicio de los años noventa, orientadas a una intervención del Estado a nivel social estructural, donde el fenómeno se planteó como una responsabilidad social colectiva, pasando luego a entenderse como una acción mayormente orientada hacia la intervención de la familia y los niños y niñas en condición de pobreza, relacionando la pobreza principalmente a responsabilidades de los sujetos identificados como pobres y sus contextos inmediatos. Con esto se tendió a una intervención que propendió a la introyección de las prácticas relacionadas a la superación de la pobreza en el cuerpo del pobre.

En los dos últimos períodos analizados, la función del Estado -respaldada en los discursos acerca de la pobreza elaborados en los marcos internacionales la ONU y la OCDE- no se orientó a lograr una mejora sustancial en cuanto a una distribución más equitativa de recursos por la vía laboral, sino que a mejorar la calidad de vida de los más pobres o vulnerables, valorándose esto como progreso social. Para ello, se incentivó la organización y la búsqueda del éxito de los grupos más pobres, desde su propio esfuerzo y capacidad de competencia, abandonando la relevancia de la incidencia del accionar gubernamental en relación a factores estructurales vinculados a la inequidad de ingresos e injusticia social, dados principalmente desde el ámbito laboral. De esa forma, la función del Estado se centró en la promoción de la igualdad de derechos, y no en la intervención en la promoción de la igualdad de posiciones como factor de pobreza, en un escenario chileno de extrema inequidad económica.

Así también, la condición de pobreza se constituyó en el transcurso del período analizado en un requisito para la focalización de las políticas sociales en sus beneficiarios y, por ende, en condicionante para el establecimiento del vínculo institucional, dependiendo la prevalencia de este del reconocimiento constante del sujeto de la identidad negativa de ser pobre, sin saberes, improductivo y sin voluntad política. De esa manera, se estableció como condición de la intervención su aceptación unilateral de las condiciones desde las cuales el gobierno definió dicha medida. Claramente, esta 
identidad impuesta no logra abarcar la totalidad de la subjetividad de quienes son enunciados, lo que resulta evidente en el contraste entre el discurso del gobierno y la percepción de la población, y en la delimitación de una serie de actuaciones que los sujetos identificados como pobres han de realizar en el proceso de socialización que exige la relación dada en el marco de las intervenciones sociales, siendo este el espacio de transformación de las funciones social de estos desde las prácticas institucionales.

De este modo, el discurso de la superación de la pobreza en Chile posibilitó una intervención fundamentalmente del Estado hacia la población más pobre, y su modelación como principales sujetos de gobierno, siendo este un instrumento, principalmente en los 90, para el manejo del malestar social, funcional para posibilitar la continuidad y desarrollo de modelo liberal impuesto en dictadura militar, y tras de ello la prevalencia de una estructura social chilena inequitativa.

Así también, este discurso se enlazó con una propuesta de desarrollo país en la que la función del Estado hacia los pobres se planteó como intervención para su incorporación al desarrollo económico del país. De este modo, en la superación de la pobreza por la vía actualmente delineada, confluyen dos objetivos. Por una parte, una mejora en la condiciones de vida de los pobres y, por otra, la generación de nuevos agentes para el desarrollo, donde el gobierno resulta ser ahora una gran empresa productora de productores, donde su principal sujeto de gobierno son los pobres o vulnerables (actualmente), y la gran promesa es que estos dejen de serlo para pasar a determinar el curso de sus vidas, desde lo económico como engranaje del desarrollo.

Finalmente, en los 20 años analizados, el gobierno ha estado dirigido desde una élite política que recuperó su lugar de poder en relación con la dictadura militar, como conglomerado orientado en el gobierno de lo social, sumando a este espacio al empresariado y a los organismos multilaterales que vinieron a intervenir directamente en las racionalidades de gobierno de lo social, en una lógica de "por el pobre pero sin el pobre". Los identificados como pobres siguen siendo considerados como sin capacidad de incidencia en la política de Estado, ninguneando sus demandas y posibilidades de participación efectiva en las decisiones políticas de Estado y, desde ello, dando continuidad a una relación entre el Estado y la población con amplia presencia en la historia de Chile, desde la cual se ha buscado diferenciar a quienes gobiernan de quienes son gobernados. 


\section{Bibliografía}

Abramovich, V. 2006. "Una aproximación al enfoque de derechos en las estrategias y políticas de desarrollo". Cepal, 88: 35-50.

Bachelet, M. 2005. Estoy Contigo. Programa de Gobierno. Michelle Bachelet, 2006-2010.

Banco Mundial. 2014. Índice GINI. Recuperado de http:// datos.bancomundial.org/indicador/SI.POV.GINI

Barros, M. 2012. "Prácticas financieras en torno al uso del crédito en la industria del retail de Santiago". Destapando la Caja Negra. Sociología de los Créditos de Consumo en Chile. Ossandón, J. (Coord.). Santiago: Instituto de Investigación en Ciencias Sociales (ICSO), 113-131.

Barry A., Osborne T. y Rose, N. 1996. Foucault and political reason. Liberalism, neo-liberalism and rationalities of government (1st ed.). Londres: Press UCL.

Bellei, C., Contreras, D. y Valenzuela, J. 2010. Ecos de la revolución pingüina. Santiago: Pehuén.

Centro de Estudios Públicos. 2011. Encuesta CEP (Estudio Nacional de Opinión Pública). Santiago: Centro de Estudios Públicos.

Chovar, A., Elgueta, K., y Salgado, H. 2010. ¿Cuánto influyen las tarjetas de crédito y los créditos hipotecarios en el sobreendeudamiento de los hogares en Chile? Santiago: Banco Central de Chile.

Coleman, J. 1990. Social Capital. Foundations of Social Theory. Harvard: The Belknap Press of Harvad University.

Consejo Nacional para la Superación de la Pobreza. 1996. La Pobreza en Chile: Un Desafío de Equidad e Integración Social.

DelaMaza, G. 2005. "Relaciones peligrosas: las políticas sociales y la sociedad civil en la transición chilena". En Cuadernos de Prácticas Sociales, Magíster de Políticas Sociales y Gestión Local (Ed.).

Dubet, F. 2012. "Los límites de la igualdad de oportunidades". Nueva Sociedad, 239: 42-50.

Fairclough, N. 2003. El análisis crítico del discurso como método para la investigación en ciencias sociales. Barcelona: Gedisa.

Fairclough, N. 1989. Language and power. Londres: Longman.

Fernández, F. 2002. "La constitución del 1980: enclaves autoritarios y cerrojos institucionales". En Memoria del VII Congreso Iberoamericano de derecho.

Filgueira, C. 2001. "Estructura de oportunidades y Vulnerabilidad Social Aproximaciones Conceptuales Recientes". En Seminario internacional Las diferentes expresiones de la vulnerabilidad social en América Latina y el Caribe.

Frías, P. 2008. Los Desafíos del Sindicalismo en los Inicios del S. XXI. Buenos Aires: CLACSO.

Fundación para la superación de la Pobreza y Universidad Diego Portales. 2011. Pobreza: 200 años de prensa escrita en pobreza. Santiago: Fundación para la superación de la pobreza y
Universidad Diego Portales.

Fundación para la superación de la pobreza. 2006. Umbrales sociales para el desarrollo. Santiago: Fundación para la superación de la pobreza.

Garretón, A. 2013. Neoliberalismo Corregido y Progresismo Limitado. Los Gobiernos de la Concertación en Chile, 1990- 2010. Santiago: Editorial Arcis y CLACSO.

Gobierno de Chile. 2009. Discurso del 21 de Mayo. Recuperado de http://www.camara.cl/camara/media/docs/ discursos/21mayo_2009.pdf

Gobierno de Chile. 2008. Discurso del 21 de Mayo. Valparaíso: Biblioteca del Congreso Nacional.

Gobierno de Chile. 2007. Discurso del 21 de Mayo. Valparaíso: Biblioteca del Congreso Nacional.

Gobierno de Chile. 2006. Discurso del 21 de Mayo. Recuperado de http://www.camara.cl/camara/media/docs/ discursos/21mayo_2006.pdf

Gobierno de Chile. 2005. Discurso del 21 de Mayo. Valparaíso: Biblioteca del Congreso Nacional.

Gobierno de Chile. 2004. Discurso del 21 de Mayo. Valparaíso: Biblioteca del Congreso Nacional.

Gobierno de Chile. 2003. Discurso del 21 de Mayo. Valparaíso: Biblioteca del Congreso Nacional.

Gobierno de Chile. 2002. Discurso del 21 de Mayo. Valparaíso:

Biblioteca del Congreso Nacional.

Gobierno de Chile. 1996. Discurso del 21 de Mayo. Valparaíso. Recuperado de http://www.camara.cl/camara/media/docs/ discursos/21mayo 1996.pdf

Gobierno de Chile. 1995. Discurso del 21 de Mayo. Valparaíso: Biblioteca del Congreso Nacional.

Gobierno de Chile. 1994. Discurso del 21 de Mayo. Valparaíso:

Biblioteca del Congreso Nacional.

Gobierno de Chile.1993. Discurso del 21 de Mayo. Valparaíso:

Biblioteca Congreso Nacional.

Gobierno de Chile. 1992. Discurso del 21 de Mayo. Valparaíso:

Biblioteca del Congreso Nacional.

Gobierno de Chile.1991. Discurso del 21 de Mayo. Valparaíso:

Biblioteca Congreso Nacional.

Gobierno de Chile. 1990. Discurso del 21 de Mayo. Valparaíso: Biblioteca del Congreso Nacional.

Godoy, O. 1999. "La Transición Chilena a la Democracia: Pactada". Estudios Públicos, 74: 79-106.

Herrera, R., Larrañaga, O. y Telias, A. 2010. La Ficha de Protección Social (Documento de Trabajo 3). Santiago: Universidad Diego Portales. Recuperado de http://www.undp.org/content/ dam/undp/documents/projects/CHL/00047878/2010_3.pdf

Ibarra. A. y Martner, G. 2006. Ciclo económico y programas de compensación social: el caso del Sistema Chile Solidario. Jackson, G. 2013. El País que soñamos. Santiago: Debate. Katzman, R. 2000. Notas sobre la medición de la vulnerabilidad 
social. Santiago: IPES-Universidad Católica de Chile.

López, R., Figueroa, E. y Gutiérrez, P. 2013. "La 'parte del león': Nuevas estimaciones de la participación de los súper ricos en el ingreso de Chile". Serie de documentos de trabajo, 379: 1-31.

Mayol, A. 2012. El Derrumbe del Modelo. La crisis económica del mercado en el Chile contemporáneo. Santiago: LOM.

Meller, P. 2011. "El problema no es el lucro, es el mercado". Revista La Onda Digital, 544.

Meyer, M. 2003. "Entre la teoría, el método y la política: la ubicación de los enfoques relacionados con el ACD". Métodos de análisis crítico del discurso. Wodak, R. y Meyer, M. (Eds.). Barcelona: Gedisa. 35-59.

Ministerio de Planificación y Cooperación. 2002. Síntesis de los principales enfoques, métodos y estrategias para la superación de la pobreza.

Ministerio de Planificación Nacional 2002. Síntesis de los principales enfoques, métodos y estrategias para la superación de la pobreza.

Ministerio de Planificación Nacional. 1991. Evolución de Políticas Sociales en Chile 1920-1991. Recuperado de http://www. ministeriodesarrollosocial.gob.cl/btca/txtcompleto/mideplan/ evol.pol.soc.1920-91.pdf

Morgado, E. 2006. Diálogo social y políticas públicas. Recuperado de http://www.escuelasindical.org/blog/wp-content/ uploads/2007/01/dialogo-social-y-politicas-publicas.pdf

Moriconi, M. 2009. "Conformar a todos: la pobreza como valor discursivo de cohesión y legitimación de la clase política chilena (1990-2000)". Revista Mexicana de Ciencias Políticas y Sociales, 206: 43-69.

Organización para la Cooperación y el Desarrollo Económico (ODCE). 2010. Chile, primer país sudamericano miembro de la OCDE. Recuperado de http://www.oecd.org/chile/ chileprimerpaissudamericanomiembrodelaocde.htm

Paz, W. 2011. El texto o discurso en la comunicación social multilingüe. Puno: Dirección Regional de Educación

Perla, P. 2007. "El Retorno de la Teoría del Capital Humano". Fundamentos En Humanidades, 8 (2): 9-26.

Programa de Naciones Unidas Para el Desarrollo (PNUD). 2013. Informe sobre Desarrollo Humano 2013. El Ascenso del Sur: Progreso Humano en un mundo diverso. Nueva York: Programa de naciones unidas para el desarrollo.

Putnam, R. 1993. Making Democracy Work: Civic Traditions in Modern Italy. Princeton: Princeton University Press.

Ramírez., S. 2001. El giro a la derecha en la reforma laboral. Recuperado de http://www.rebelion.org/hemeroteca/sociales/ ramirez2150401.htm

Rauber, I. 2003. Los Dilemas del sujeto. Movimiento social y organización política en América Latina. Lógicas en conflicto. Reflexiones acerca del sujeto sociopolítico de la transformación social latinoamericana en el siglo XXI. Recuperado de www. nodo50.org/cubasigloXXI/.../ponencias.htm, 9-10.

Riffo, J. 2008. Historia y anécdotas del discurso del 21 de mayo. Recuperado de http://www.bcn.cl/de-que-se-habla/ historia-y-anecdotas-del-discurso-del-21-de-mayo

Schkolnik, M. y García, A. 1995. "Superación de la pobreza: Balance y propuestas". Políticas económicas y Sociales en el Chile Democrático. Vial, C., Raczynski, J. y Pizarro, D. (Ed.) . Santiago: CIEPLAN. 141-166. Recuperado de http://www.cieplan. org/media/publicaciones/archivos/15/Capitulo_7.pdf

Serrano, C, 2005. Familia como unidad de intervención de políticas sociales. Notas sobre el Programa Puente - Chile solidario. Recuperado de http://www.eclac.org/dds/noticias/ paginas/2/21682/Claudia_Serrano.pdf

Serrano, C. y Raczynski, D. 2004. Programas Sociales Innovadores de Superación de la Pobreza en Brasil y Chile. Santiago: LOM.

Solimano, A. y Pollack, M. 2006. La mesa coja. Santiago: Colecciones CIGLOB. Recuperado de http://www.ciglob.org/ inicio/publicaciones/libros/ciglob/la-mesa-coja.html

Thaylor, L. 1998. El Crecimiento, El Estado y la Teoría del Desarrollo. En Los caminos de la prosperidad, México; Fondo de Cultura Económica.

Torres, R. 2010. Juventud, resistencia y cambio social: el movimiento de estudiantes secundarios como un "actor político" en la sociedad chilena post- Pinochet (1986-2006). Ponencia presentada en Independencias - Dependencias Interdependencias, VI Congreso CEISAL, Toulouse, Francia.

Van Dijk, T. 1999. "¿Qué es el análisis del discuso político?” Análisis del discurso social y político. Van Dijk, T. y Mendizábal, I. (Eds.). Quito: Abya-Yala. 9-102. 
